\title{
Collagenous inflammatory mucosal diseases of the gastrointestinal tract
}

\author{
HUGH J FREEMAN, MD, FRCPC, FACP
}

\begin{abstract}
A new group of collagenous inflammatory disorders of the gastric and intestinal mucosa has been described in the past two decades. These entities appear to be characterized by a distinct histopathologic lesion in the subepithelial region of the lamina propria. Functional alterations may also occur, presumably related to collagen deposition and the associated inflammatory process. Collagenous sprue is characterized by progressive and unrelenting malabsorption; a lethal outcome has usually been described, possibly reflecting the site of collagen deposition and the critical role of the small bowel for maintenance of a normal nutritional state. In contrast, collagenous colitis is characterized by persisting or episodic watery diarrhea; clinical impairment appears to be less severe but the entity is not rare, possibly reflecting its colonic localization. Most recently, collagenous gastritis, possibly accompanied by a functional reduction in acid secretion and impaired gastric emptying, has been recognized. Further definition of these entities is still required, particularly in relation to etiology, pathogenesis and effective therapy. Can J Gastroenterol 1990;4(5):196-200
\end{abstract}

Key Words: Collagenous colitis, Collagenous gastritis, Collagenous sprue, Diarrhea, Inflammatory bowel diseases, Malabsorption

\section{Les collagenoses des voies gastro-intestinales}

RESUME: Un nouveau groupe de collagénoses atteignant la muqueuse gastrique et intestinale ont été décrites au cours des deux dernières décennies. Ces entités semblent caractérisées par une lésion histopathologique distincte située dans la région sous-épithéliale du chorion de la muqueuse gastrique ou intestinale. Des altérations fonctionnelles peuvent également survenir; on présume qu'elles résultent du dépôt de collagène et du processus inflammatoire associé. La sprue du collagène se.caractérise par une malabsorption progressive et inexorable. L'issue est habituellement fatale et reflète peut-être le site du dépôt de collagène et le rôle essentiel du grêle dans le maintien de l'état nutritionnel. Par contre, la colite du collagène est caractérisée par des épisodes persistants ou épisodiques de diarrhée aqueuse; la détérioration clinique semble moins sérieuse mais l'entité n'est pas rare et correspond peut-être à une atteinte colique. Plus récemment, la gastrite du collagène - peut-être accompagnée d'une réduction fonctionnelle de la sécrétion acide et de l'évacuation gastriques - a été reconnue. De plus amples définitions de ces entités sont requises, surtout en matière d'étiologie, de pathogenèse et de traitement efficace.

Department of Medicine (Gastroenterology), University Hospital and University of British Columbia, Vancouver, British Columbia

Correspondence and reprints: Dr Hugh Freeman, Gastroenterology, ACU F-137, University Hospital (UBC), 2211 Westrook Mall, Vancouver, British Columbia V6T IW5. Telephone (604) $228-7216$

Received for publication March 5, 1990. Accepted May 30, 1990
$\mathrm{D}$ URING THE PAST TWO DECADES, a group of very intriguing gastrointestinal diseases has emerged that are increasingly being recognized as ap. parently distinctive clinicopathologic entities. These are the collagenous disorders of the gastrointestinal tract, comprising collagenous sprue, collagenous colitis and, more recently, collagenous gastritis. All have a characteristic and unique histopathologic lesion in the subepithelial basement membrane region of gastric or small or large intestinal biopsy material, consisting of eosinophilic hyaline deposits in routinely stained hematoxylin-eosin sections; these deposits are trichromereactive, typical of collagen. This paper reviews the clinical and pathological features of these diseases.

\section{COLLAGENOUS SPRUE}

In 1970, Weinstein et al (1) reported their observation of an ap. parently unusual light microscopic ab. normality of the small intestinal mucosa in a 51-year-old woman initially believed to have a gluten-sensitive enteropathy with refractory malabsorption. This histologic lesion contained eosinophilic hyaline material in the lamina propria of the small intestinal mucosa, and histochemical studies revealed that it had the staining characteristics of collagen. A review of her initial biopsies showed features typical of celiac sprue, but convincing evidence for a clinical and histologic response to a gluten-free diet was not demonstrable. Ultrastructural studies 
of the hyaline deposits confirmed the presence of a zone of electron-dense amorphous material with the characteristic $640 \AA$ axial periodicity of collagen fibres. The patient's progressively deteriorating clinical course was seemingly parallelled by a worsening severity of this pathological process; she died less than four years after her initial presentation with continuing malabsorption, diarrhea and weight loss. In addition to apparent refractoriness to a strict gluten-free diet in hospital on a metabolic ward, nutritional repletion, lactose-free and low fat diets, and pharmacologic intervention with antibiotics, sulphasalazine and pancreatic enzymes produced no beneficial results. Corticosteroids appeared to provide some temporary amelioration of the diarrhea.

Careful pathologic studies of the entire length of the small bowel obtained with a hydraulic small intestinal suction biopsy instrument revealed that most of the small bowel was devoid of villi with short segments of virtually normal small bowel mucosa in the middle and distal small bowel; eosinophilic hyaline material was present in the lamina propria to varying degrees of thickness in abnormal areas. Extensive studies failed to reveal a specific cause for this disorder, although the author suggested that an identical lesion may have been observed in a report of two patients by Schein in 1947 (2) and in another of one patient by Hourihane in 1963 (3). In the latter report, small intestinal changes were extensive and included ileal mucosal atrophy with collagenous hyaline deposition. By 1978 , at least 10 patients had been described, some in duplicated reports or review articles (4-15), all with similar clinicopathologic features - severe and sometimes longstanding malabsorption, 'flattened' small intestinal villous architecture and distinctive subepithelial collagenous deposits. Abdominal pain, diarrhea and weight loss were common features, and vasculitis was occasionally reported $(1,10)$. The collagenous deposits appeared to be patchy or very focal in distribution rather than diffuse, usually with variable alterations in villous architecture; collagen deposits were also variable in thickness, even at similar sites in the small intestine. In some of these reports $(1,11)$, corticosteroids may have been beneficial at least in providing some temporary clinical improvement. Because the pathologic lesion is so variable in its distribution and severity, however, convincing evidence for histologic improvement in response to specific therapeutic modalities is not available.

The precise relationship, if any, to celiac sprue still remains controversial. In one study (16), small intestinal mucosal biopsies from patients with celiac sprue or 'sprue-like' small bowel disease revealed various degrees of basement membrane and subepithelial collagen deposition; it was believed that this possibly represented a nonspecific injury reaction rather than a 'new disease.' However, the lesion was observed in the lamina propria (ie, 'grade 3' lesions) in only $8 \%$ of 146 patients studied with a diagnosis of celiac sprue, and not in other small bowel diseases. Of this $8 \%$, six patients with subepithelial collagen extending into the lamina propria were studied to determine the role, if any, of a gluten-free diet. No histologic response was seen in three patients, and among these, unremitting malabsorption and death occurred in two; in the other three patients, subepithelial collagen was not observed after gluten-free diet therapy, although this may have been due to sampling error. These findings suggested that marked subepithelial collagen deposition may be a morphologic marker of a poor outcome in celiac sprue (16). In contrast, others have viewed collagenous sprue as a distinct small bowel disorder that is progressive, poorly responsive or unresponsive to a gluten-free diet and characterized by unremitting malabsorption and an inevitably lethal outcome $(1,4,5,17)$.

Localization of the collagen band to the subepithelial zone led to the hypothesis of altered pericryptal fibroblast turnover (18). It is thought that these cells normally migrate and mature in parallel with adjacent crypt and villus epithelial cells $(19,20)$. Prema- ture and excessive collagen formation in the lamina propria might result from impaired turnover of these cells. Alternatively, fibrosis at this site may relate to the proximity of this region of the lamina propria to noxious environmental factors in the small intestinal lumen. Genetic factors could also modulate the appearance of this lesion, since fibrogenesis may be altered in other primarily genetically determined disorders, such as Gardner's syndrome (eg, keloids and postoperative mesenteric fibrosis). Immunologic mechanisms operative in the lamina propria are also likely to be involved, particularly since increased lymphocytes and plasma cells are present, which are often embedded in the matrix of the thick collagenous deposits. Moreover, bronchial tissues in asthma may develop similar pathologic changes suggestive of an immune pathogenesis (21). Additional studies are needed to elucidate the cause and development of this lesion so that a more specific therapeutic approach might be developed.

\section{COLLAGENOUS COLITIS}

In January 1976, two reports $(22,23)$ appeared that independently described unique and previously unrecorded histopathologic features in colorectal biopsies from a total of three patients with a watery diarrhea syndrome. In each of the patients, the endoscopic and/or macroscopic appearances of the colonic mucosa were normal. However, specific microscopic changes were present. In particular, a subepithelial hyaline band was present in the lamina propria associated with increased numbers of lamina propria lymphocytes and plasma cells. In both reports, the deposits failed to react histochemically with amyloid, but stained with trichrome, typical of collagen. In addition, ultrastructural studies in one of these reports (22) confirmed the presence of collagen fibres. The term 'collagenous colitis' was proposed (23), in part because of the syndrome's histopathologic similarities to collagenous sprue. Since these initial reports, well over 50 additional cases have been described in the English language literature (18,24-62). 
Most patients, as recently reviewed elsewhere $(63,64)$, are usually, but not exclusively, females over the age of 50 years. The diarrhea is characteristically watery and nonbloody, often associated with vague abdominal cramping discomfort or pain, as well as variable weight loss. Although symptoms may be longstanding and present for several months or years, investigations to elucidate the cause are usually normal. In most, radiographic and colonoscopic examinations are normal. In a few patients, minimal or nonspecific changes including hyperemia, 'patchy white areas' or mucosal 'edema' have been described (63). The diagnosis is usually made only after recognition of the characteristic histopathologic lesion in a colorectal mucosal biopsy. Thus, in order to exclude this disorder in patients with chronic diarrhea syndromes, the clinical approach should include colorectal biopsy even if the endoscopic appearance is normal.

Routine staining of colon sections with hematoxylin and eosin reveals a homogeneous band of eosinophilic material in the subepithelial region. The lesion is most evident between crypts, and multiple biopsies may indicate a patchy or focal distribution rather than continuous or diffuse involvement. Increased numbers of chronic inflammatory cells are present in the lamina propria, including lymphocytes and plasma cells; often, these cells appear entrapped in the collagenous meshwork. In some sections of the biopsy, the surface epithelium appears denuded; this finding could represent artefact but probably represents a real pathologic change. The lesion is reported to be birefringent in polarized light (25), stains pale pink with periodic acid Schiff reagent and positively with trichrome staining. Rarely, polymorphonuclear leukocytes are observed invading the epithelium, and in some, colonic mucosal height is reduced. In most patients, the actual thickness of this band-like deposit is over $10 \mu \mathrm{m}(25,28)$. Unfortunately, precise measurements of thickness, although possibly helpful for descriptive purposes, have no diagnostic value.
Moreover, symptoms do not correlate with quantitation of lesion thickness in a single biopsy. In most, the lesion is variable, depending possibly in part on fixation and staining methods; in some areas of a sample biopsy, no lesion may be present. As for collagenous sprue, extension into the lamina propria with entrapment of lamina propria plasma cells and lymphocytes is probably the most important histologic feature.

Ultrastructural studies $(22,26,28,40)$ have confirmed the presence of material with the characteristic axial periodicity of collagen fibres. These appear longitudinal on cross-section and may be accompanied by microfibrils, ground substance and amorphous proteins. Increased numbers of immunoglobulin-containing cells in the lamina propria have been observed in some patients. Recent reports have also provided immunohistochemical evidence that some of the trapped fusiform and/or stellate cells within the deposits are myoid cells, being positive with antibodies against smooth muscle cell alpha-actin (62). In others, immunofluorescent studies have failed to identify immunoglobulins, complement, albumin or fibrinogen (65), suggesting that some components of this lesion may vary from patient to patient. Finally, immunofluorescent methods have also shown increased deposition of collagen types I and III, as well as fibronectin $(40,65)$.

Although watery diarrhea of prolonged duration is a characteristic clinical feature, the pathogenesis of this diarrhea is not clear. By itself, the histotogic change may not be responsible for diarrhea. Support for a secretory mechanism is derived from studies in patients with persistent diarrhea despite fasting for up to $72 \mathrm{~h}$. Whole colon perfusion demonstrated profuse fluid and electrolyte secretion, while in vivo fecal dialysis showed increased immunoreactive prostaglandin $\mathrm{E}_{2}$ levels. In other studies, pancreatic and small bowel function has been normal. In addition, thyroid function and levels of gastrin, glucagon, calcitonin, vasoactive intestinal peptide, urinary 5 -hydroxyindoleacetic acid, catecholamine and metanephrines have been normal $(34,42)$. Finally, small intestinal biopsies have generally been described as normal (26-29), although there are some recent descriptions of severe 'flat' small intestinal biopsy changes typical of celiac sprue in patients with collagenous colitis (51). Recently, coexistent collagenous sprue and colitis were recorded, and coined 'collagenous enterocolitis' (18). Some researchers, however, view this observation as simp. ly the presence of two separate and un. common diseases in the same patient rather than a single entity (66).

The pathogenesis and natural history of this disorder requires definition. The histopathologic description of this entity appears to be evolving. Some researchers initially suggested that mucosal inflammatory changes of an acute colitis, so-called 'microscopic colitis' (67), may occur in conjunction with or precede the more typical changes of collagenous colitis $(50,56)$. In these patients, microbiologic investigations were uniformly negative during both the apparent initial acute colitis phase of the illness and the more chronic phase. Subsequently, the term 'lymphocytic colitis' was used to describe a clinicopathologic syndrome of watery diarrhea, grossly normal colonoscopy and mucosal inflammatory changes. The major distin. guishing feature of this microscopic colitis was the presence of intraepithelial lymphocytes. This entity is felt to be histologically very distinct from idiopathic inflammatory bowel disease and acute forms of colitis; it differs from collagenous colitis in that subepithelial collagen thickening is seen only in collagenous colitis (68). A number of pathogenetic mechanisms for this lesion have been raised (44). Fibroblast turnover may be reduced (as suggested in collagenous sprue), resulting in a mature fibroblast population that produces more collagen, possibly due to a longer life span.

Alternatively, the collagen band may be related to preceding inflamma. tion and ulceration with resultant stimulation of collagen synthesis, or to a defect in regulatory control. Or, final. ly, the disease may be similar to the 
hyaline vascular sclerosis seen in hypertension or diabetes with vascular leakage of plasma proteins in the absence of inflammation, so-called 'plasmatic vasculosis' (69). Long periods of spontaneous clinical remission with intermittent exacerbations of watery diarrhea may occur (38). In other patients, symptoms may be continuous. Treatment responses to sulphasalazine $(36,41,57,61)$, mepacrine (27), metronidazole (39), antidiarrheal agents $(34,42)$ and steroids $(24,41,51)$ have been reported, but follow-up is often limited. In some cases, partial or complete resolution of the histological marker has been described.

Intestinal and extraintestinal complications analogous to those in inflammatory bowel disease have been apparently unusual. Adenocarcinoma has been recorded in a single patient (70); it also appears in patients with celiac sprue (51) and Crohn's disease of

\section{REFERENCES}

1. Weinstein WM, Saunders DR, Tytgat GN, Rubin CE. Collagenous sprue An unrecognized type of malabsorption. N Engl J Med 1970;283:1297-301.

2. Schein J. Syndrome of nontropical sprue with hitherto undescribed lesions of the intestine. Gastroenteroly 1947;8:438-60.

3. Hourihane DO'B. The histology of intestinal biopsies. Proc R Soc Med 1963;56:1073-7.

4. Hines HW, Aldersberg D. Pathologic studies in idiopathic sprue. J Mt Sinai Hosp 1957;24:251-72.

5. Barry RE, Morris JS, Read AE. A case of small intestinal mucosal atrophy. Gut 1970;11:743-7.

6. Barry RE, Morris JS, Read AE. Collagenous sprue. N Engl J Med 1971;284:1041. (Lett)

7. Neale G. Clinicopathological conference. Case of adult coeliac disease resistant to treatment.

Br Med J 1968;2:678-84.

8. Booth CC. The enterocyte in coeliac disease. Br Med J 1970;4:14-7.

9. Doe WF, Evans D, Hobbs JR, Booth CC. Coeliac disease, vasculitis, and cryoglobulinemia. Gut 1972;13:112. 23.

10. Holdstock DJ, Oleesky S. Vasculitis in coeliac disease. Br Med J 1970;4:369.

11. Holdstock DJ, Oleesky S. Successful treatment of collagenous sprue with combination of prednisolone and the small and large bowel (53). Arthropathy or frank arthritis $(32,37$, $41,57)$, thyroid disease (50) and pulmonary fibrosis (49) have been noted, raising the possibility of a more generalized autoimmune disorder $(49,50)$. Undoubtedly, as recognition of this entity increases, its full clinical spectrum will unfold.

\section{COLLAGENOUS GASTRITIS}

In November/December 1989, two reports independently described an apparently new form of chronic gastritis, histologically characterized by subepithelial collagenous deposits. In both reports $(71,72)$, including one recorded in this Journal (71), the entity was termed 'collagenous gastritis.' One patient was a 54-year-old female with recurrent nausea, vomiting and weight loss associated with radiographic evidence of impaired gastric emptying and a requirement for parenteral nutrition.

gluten-free diet. Postgrad Med ] 1973;49:664-7.

12. Sheehy TW, Staats OJ. Collagenous sprue. A case report. Ala J Med Sci 1972;9:392-6.

13. Dowling RH, Henry K. Clinicopathological conference. Non-responsive coeliac disease. Br Med J 1972;4:369.

14. Pepper HW, Brandborg LL, Shanser, JD, Goldberg HI, Moss AA. Col. lagenous sprue. Am J Roentgenol Radiol Ther Nucl Med 1974;121:275. 82.

15. Zeman RK, Tomer RG. Collagenous sprue. Am J Gastroenterol 1978;70:541-4

16. Bossart R. Henry K, Both CC, Woe WF. Subepithelial collagen in intestinal malabsorption. Gut 1975;16:1822.

17. Perera DR, Weinstein WM, Rubin CE. Small intestinal biopsy. Hum Pathol 1975;6:157-217.

18. Eckstein RP, Dowsett JF, Riley JW. Collagenous enterocolitis: A case of collagenous colitis with involvement of the small intestine. Am J Gastroenterol 1988;83:767-71.

19. Pascal RR, Kaye GI, Lane N. Colonic pericryptal fibroblast sheath: Replication, migration, and cytodifferentiation of a mesenchymal cell system in adult tissue. I. Autoradiographic studies of normal rabbit colon. Gastroenterology 1968;54:835-51.

20. Kaye GI, Lane N, Pascal RR. Colonic
Another patient was a 15-year-old female with recurrent abdominal pain and upper gastrointestinal bleeding. In both patients, no clinical or pathological improvement was evident despite the use of a number of medications including antacids, $\mathrm{H}_{2}$ blockers, prokinetic agents (ie, metoclopramide), carbenoxalone and sucralfate. In both patients, biopsies of the small and large intestine did not reveal collagenous deposits. An immune-mediated pathogenesis, possibly resulting in altered function of lamina propria fibroblasts and altered collagen turnover, may be responsible.

Recently, the authors have also reported observations of lymphocytic gastritis and colitis in patients with celiac sprue $(73,74)$. The relationship of these entities to this histopathologic spectrum of collagenous mucosal inflammatory diseases, although intriguing, is not clear.

pericryptal fibroblast sheath: Replication, migration, and cytodifferentiation of a mesenchymal cell system in adult tissue. III. Fine structural aspects of normal rabbit and human colon. Gastroenterology 1968;54:852-65.

21. Callerame ML, Condemi JJ, Bohrod MG, Vaughan JH. Immunologic reactions of bronchial tissues in asthma. N Engl J Med 1971;284:459. 64.

22. Freeman HJ, Weinstein WM, Shnitka TK, Wensel RH, Sartor VE. Watery diarrhea syndrome associated with a lesion of the colonic basement membrane (BM)-lamina propria (LP) interface. Ann R Coll Phys Surg Can $1976 ; 9: 45$

23. Lindst rom CG. Collagenous colitis with watery diarrhea - A new entity? Pathol Eur 1976;11:87-9.

24. Nielsen VT, Vetner M, Harsly E. Collagenous colitis. Histopathology 1980;4:83-6.

25. Bogomoletz WV, Adret JJ, Birembaut P, Feydy P, Dupont P. Collagenous colitis: An unrecognized entity. Gut 1980;21:164-8.

26. Teglbjaerg PS, Thaysen EH. Collagenous colitis: An ultrastructural study of a case. Gastroenterology 1982;82:561-3.

27. Preterse AS, Hecker R, Rowland R. Collagenous colitis: A distinctive and potentially reversible disorder. J Clin Pathol 1982;35:338-40.

28. van den Oord J], Geboes K, Desmet 
VJ. Collagenous colitis: An abnormal collagen table? Two new cases and review of the literature. Am J Gastroenterol 1982;77:377-81.

29. Colina F, Solis-Herruzo JA, MunozYague MT, Vazquez G, Perez-Barrios A. Collagenous colitis: The clinical and morphological features. Postgrad Med ] 1982:58:390-5.

30. Bamford MJ, Metz LR, Armstrong JA, Harris AR. Collagenous colitis: A case report and review of the literature. Pathology 1982;14:481-4.

31. Grouls V, Vogel J, Sorger M. Collagenous colitis. Endoscopy 1982;14:31-3.

32. Erlendsson J, Fenger C, Meinicke J. Arthritis and collagenous colitis. Report of a case with concomitant chronic polyarthritis and collagenous colitis. Scand J Rheumatol 1983:12:93-5.

33. Guarda LA, Nelson RS, Stroehlein JR, Korinek JK, Raymond AK. Collagenous colitis. Am J Clin Pathol 1983;80:503-7.

34. Rask-Madsen J, Grove O, Hansen MGJ, Bukhave K, Scient C, HenrikNielsen R. Colonic transport of water and electrolytes in a patient with secretory diarrhea due to collagenous colitis. Dig Dis Sci 1983;28:1141-6.

35. Yeshaya C, Novis B, Bemheim J, Leictmann G, Samara M, Griffel B. Collagenous colitis. Report of a case. Dis Colon Rectum 1984:27:111-3.

36. Weidner N, Smith J, Pattee B. Sulfasalazine in tseatment of collagenous colitis. Case report and review of the literature. Am J Med 1984;77:162-6.

37. Teglbjaerg PS, Thaysen EH, Jensen $\mathrm{HH}$. Development of collagenous colitis in sequential biopsy specimens. Gastroenterology 1984;87:703-9.

38. Debongnie JC, De Galocsy C, Caholessur MO, Haot ]. Collagenous colitis: A transient condition? Report of two cases. Dis Colon Rectum 1984;27:672-6.

39. Mogensen AM, Olsen JH, GudmandHoyer E. Collagenous colitis. Acta Med Scand 1984:216:535-40.

40. Flejou JF, Grimaud JA, Molas G, Baviera E, Potet F. Collagenous colitis: Ultrastructural study and collagen immunotyping of four cases. Arch Pathol Lab Med 1984;108:977-82.

41. Farah DA, Niis PR, Lee FD, McLay A, Russell RI. Collagenous colitis: Possible response to sulfasalazine and local steroid therapy. Gastroenterology 1985;88:792-7.

42. Eaves ER, Wallis PL, Mclntyre RLE, Korman MG. Collagenous colitis: A recently recognized reversible clinicopathologic entity. Aust N Z J Med $1983: 13: 630-2$
43. Fausa O, Foeester A, Hovig T. Collagenous colitis. A clinical, histological, and ultrastructural study. Scand J Gastroenterol Suppl 1985;107:8-23.

44. Kingham JG, Levison DA, Morson $\mathrm{BC}$, Dawson AM. Collagenous colitis. Gut 1986;27:570-7.

45. Palmer KR, Berry H, Wheeler PJ, et al. Collagenous colitis - A relapsing and remitting disease. Gut 1986;27:578-80.

46. Hwang WS, Kelly JS, Shaffer EA, Hershfield NB. Collagenous colitis: A disease of pericryptal fibroblast sheath? J Parhol 1986;149:33-40.

47. Stueland DT, Gani KS, Magnin GE, Norfleet RG. Collagenous colitis: Report of a case with autopsy data. Wis Med J 1986;85:26-7.

48. Coverlizza S, Ferrari A, Scevola F, et al. Clinico-pathologic features of collagenous colit is: Case report and literature review. Am J Gastroenterol 1986;81:1098-103

49. Wiener NO, Collagenous colit is and pulmonary fibrosis. Manifestations of a single disease? J Clin Gastroenterol 1986;8:677-80.

50. Giardieflo FM, Bayless TM, Jessurun J, Hamilton SR, Yardley JH. Collagenous colitis: Physiologic and histopathologic studies in seven patients. Ann Intern Med 1987;106:46-9.

51. Hamilton I, Sanders S, Hopwood D, Bouchier IA. Collagenous colitis associated with small intestinal villous atrophy. Gut 1986;27:1394-8.

52. Salt WB, Llaneza PP, Collagenous colitis: A cause of chronic diarrhea diagnosed only by biopsy of normal appearing colonic mucosa. Gastrointest Endosc 1986;32:421-3.

53. Chandratre S, Bramble MG, Cooke WM, Jones RA. Simultaneous occurrence of collagenous colitis and Crohn's disease. Digestion 1987;36:55-60.

54. Prior A, Lessells AM, Whorwell PJ. Is biopsy necessary if colonoscopy is normal? Dig Dis Sci 1987:32:673-6.

55. Wang KK, Perrault J, Carpenter HA, Schroeder KW, Tremaine WJ. Collagenous colitis: A clinicopathologic correlation. Mayo Clin Proc 1987;62:665-71

56. Jessurun J, Yardley JH, Giardiello FM, Hamilton SR, Bayless TM. Chronic colitis with thickening of the subepithelial collagen layer (collagenous colitis): Histoparhologic findings in 15 patients. Hum Pathol 1987;18:839-48.

57. Wengrower D, Pollak A, Olson E, Stalnikowicz R. Collagenous colitis and rheumatoid arthritis with response to sulfasalazine. A case report and review of the literature. J Clin Gastroenterol 1987:9:456-60.
58. Danji JT, McDonald TJ, King J. Collagenous colitis. Am J Gastroenterol 1988;83:83-5.

59. Janssens L, Eycken M, Vanderzchueren D, et al. Collagenous colitis. Report of three cases and review of the literature. Acta Clin Belg 1988;43:27-33.

60. Nussinson E, Samara M, Vigder L, Shafer I, Tzur N. Concurrent collagenous colitis and multiple ileal carcinoids. Dig Dis Sci 1988;33:1040-4

61. Rokkas T, Filipe MI, Sladen GE. Collagenous colitis with rapid response to sulphasalazine. Postgrad Med ] 1988;64:74-6.

62. Widgren S, Jlidi R, Cox JN. Collagenous colitis: Histologic, morphometric, immunohistochemical and ultrastructural studies. Report of 21 cases. Virchows Arch [A] 1988;413:287-96

63. Rams H, Rogers AI, Ghandun-Mnaymneh L. Collagenous colitis. Ann Intern Med 1987;106:108-113.

64. Freeman HJ. Collagenous colitis. In: Freeman HJ, ed. Inflammatory Bowel Disease, Vol 2. Boca Raton: CRC Press, 1989:75-81.

65. Bogomoletz WV. Collagenous colitis: A clinicopathological review. Surv Dig Dis 1983:1:19-25.

66. Norfleet RG, Magnin GE, Stueland DT, Gani KS. Collagenous enterocolitis or colitis? Am J Gastroenterol 1989;84:86-7

67. Kingham JGC, Levison DA, Ball JA, Dawson AM. Microscopic colitis - A cause of chronic watery diarrhea. Br Med J 1982;285:1601-4.

68. Lazenby AJ, Yardley JH, Giardiello FM, Jessurun J, Bayless TM. Lymphocytic ("microscopic") colitis. A comparative histopathologic study with particular reference to collagenous colitis. Hum Pathol 1989;20:18-28.

69. Anon. Collagenous colitis. Lancet 1986;ii:1136-7. (Edit)

70. Gardener GW, Goldberg R, Currie D, Murray D. Colonic carcinoma associated with an abnormal collagen table. Cancer 1984:54:2973-7.

71. Freeman HJ, Piercey JRA, Raine RJ. Collagenous gastritis. Can J Gastroenterol 1989:3:171-4.

72. Colletti RB, Trainer TD. Collagenous gastritis. Gastroenterology 1989;97:1552-5.

73. Wolber R, Owen D, Delbuono L, Appelman H, Freeman H. Lymphocytic gastritis in patients with celiac sprue or spruelike intestinal disease. Gastroenterology 1990;98:310-5.

74. Wolber R, Owen D, Freeman H. Lymphocytic colitis in patients with celiac sprue. Hum Pathol. (In press) 


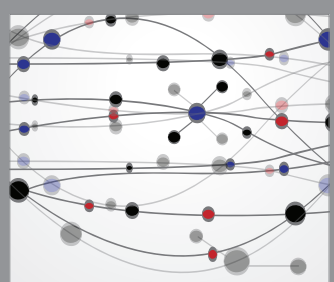

The Scientific World Journal
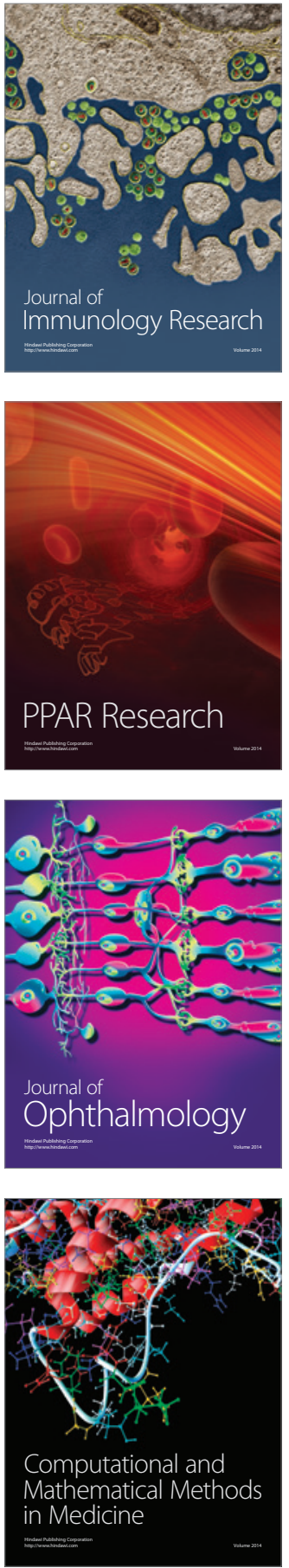

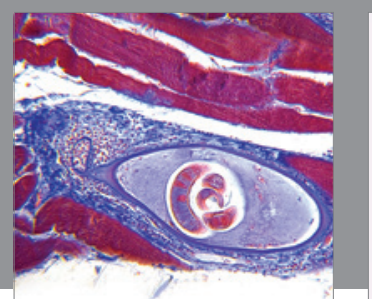

Gastroenterology Research and Practice

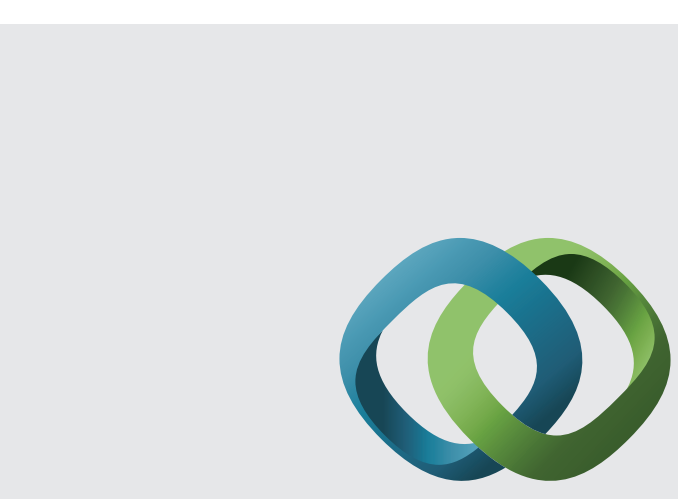

\section{Hindawi}

Submit your manuscripts at

http://www.hindawi.com
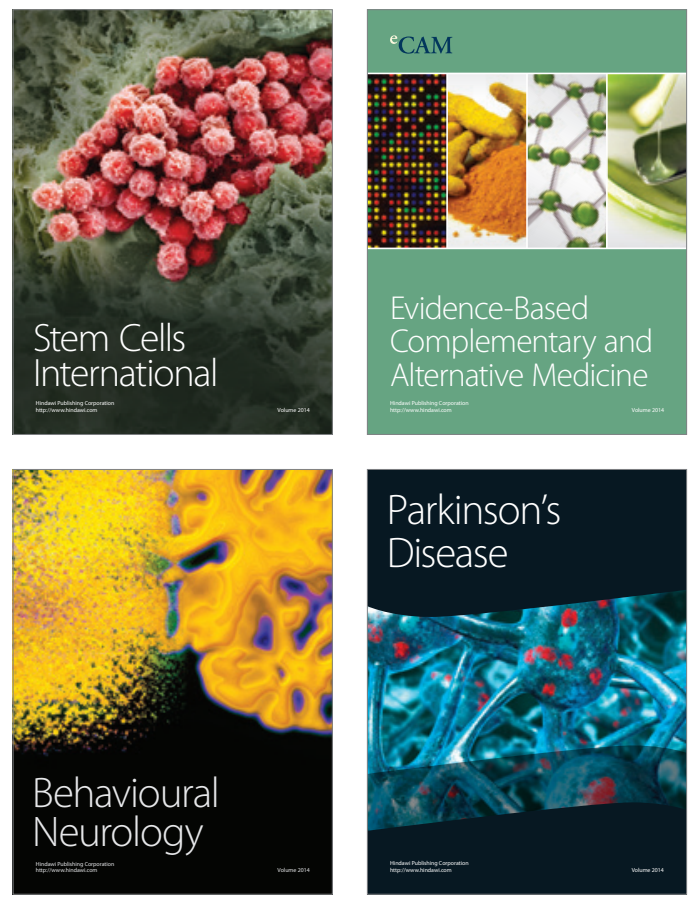
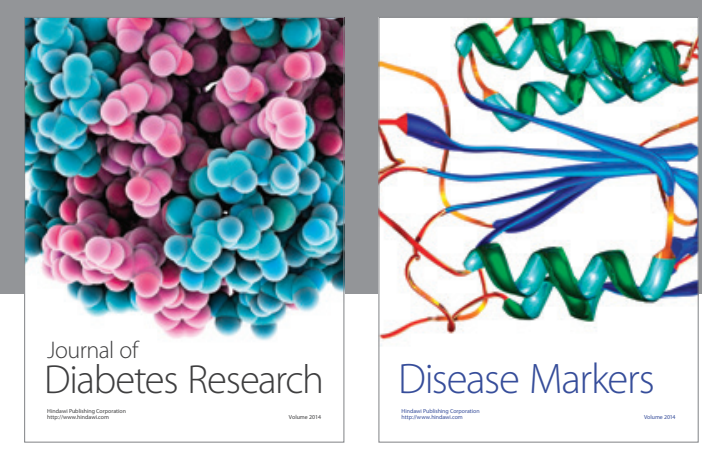

Disease Markers
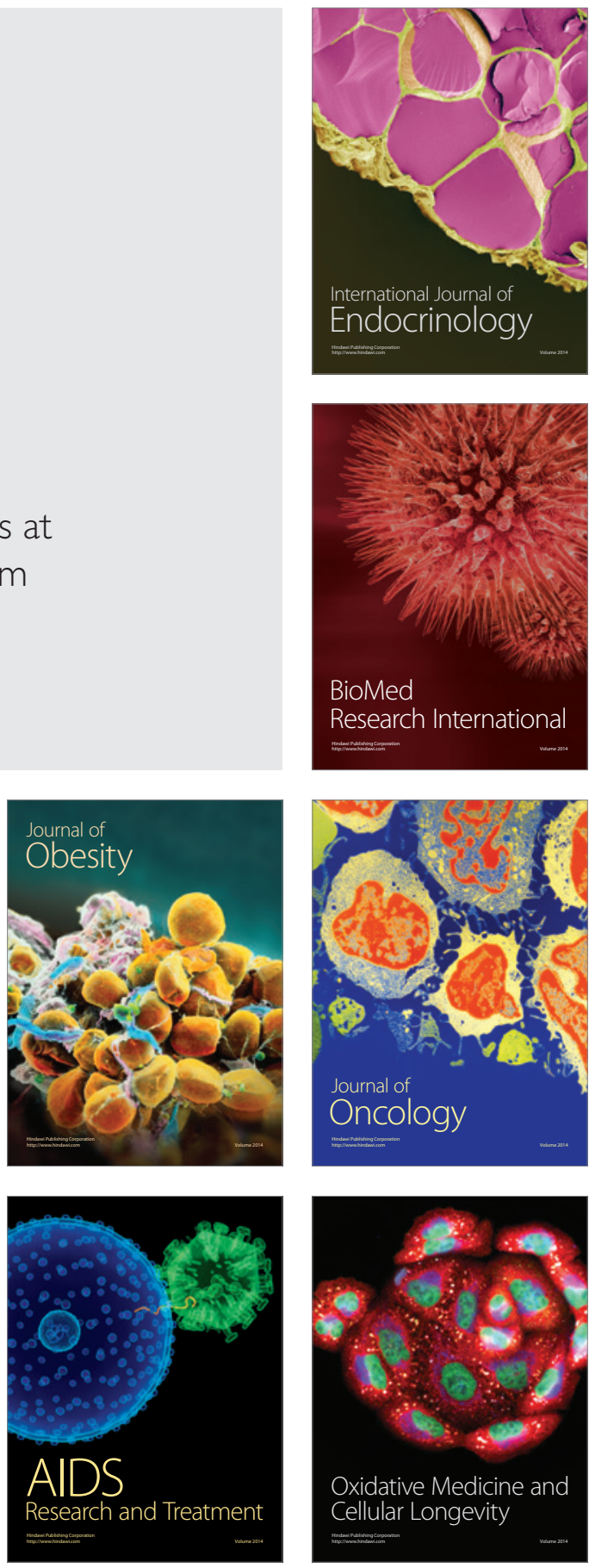